\title{
APPLICATION OF AN MEMETIC ALGORITHM TO PLACEMENT OF SENSORS FOR ACTIVE NOISE-VIBRATION CONTROL
}

\begin{abstract}
For successful active control of a vibrating structure it is essential to appropriately place sensors. One of the most important criteria is to make the system observable, so any control objectives can be achieved.

In this paper the observability-oriented placement of sensors is undertaken. First, a theoretical model of a fully clamped plate is presented. Optimization criterion based on maximization of observability of the system is developed. A memetic algorithm is used to find the optimal solution. Obtained results are compared with those obtained by the genetic algorithm. The configuration is also validated experimentally.
\end{abstract}

Keywords: active control, flexible structures, sensor placement, observability Gramian, genetic algorithm, memetic algorithm

\section{ZASTOSOWANIE ALGORYTMU MEMETYCZNEGO DO ROZMIESZCZENIA CZUJNIKÓW W CELU AKTYWNEJ REDUKCJI DRGAŃ I HAEASU}

W celu skutecznej aktywnej redukcji drgań i hałasu konstrukcji konieczne jest odpowiednie rozmieszczenie czujników. Jednym z najważniejszych kryteriów jest uczynienie obiektu obserwowalnym, aby jakiekolwiek cele sterowania mogły zostać osiagnięte.

W pracy podjęte zostało zagadnienie rozmieszczenia czujników w oparciu o analizę obserwowalności. Zaprezentowany zostat model teoretyczny ptyty o brzegach calkowicie utwierdzonych. Wyprowadzone zostało kryterium optymalizacji $w$ oparciu o maksymalizacje miary obserwowalności. Do znalezienia rozwiazania optymalnego zastosowano algorytm memetyczny. Otrzymane wyniki zostały porównane z wynikami uzyskanymi za pomoca algorytmu genetycznego. Wyznaczone rozmieszczenie czujników zostało zweryfikowane eksperymentalnie.

Stowa kluczowe: aktywna redukcja drgań i hałasu, elastyczne struktury, rozmieszczenie czujników, macierz Grama obserwowalności, algorytm genetyczny, algorytm memetyczny

\section{INTRODUCTION}

Structure-borne sound emission has been investigated in recent years by different authors (Szemela et al. 2012, Górski and Kozupa 2012). Active noise-vibration control systems often rely on structural sound sources (Pawełczyk 2008, Leniowska 2011, Kozupa and Wiciak 2010, Mazur and Pawełczyk 2011). However, for successful active control of a vibrating structure it is essential to possess relevant information about its current state. Misplaced sensors may result in the faint measure of particular vibration modes or even a complete lack of observability. This may have a negative impact on the system performance. Hence, their locations have to be carefully chosen.

Optimal sensor placement methods presented in the literature can be divided into two groups. One approach is based on simultaneous optimization of sensors locations and controller parameters. AN optimization index in the form of the performance of an LQR controller is proposed in (Kumar and Narayanan 2007). Objective function in the form of the spatial $\mathrm{H}_{2}$ norm of the closed-loop system is considered in (Liu et al. 2006).
Another approach concentrates on open-loop system analysis, which is independent of control strategy. The observability gramian is used in optimization criterion in (Leleu et al. 2001). Modified $H_{\infty}$ norm for the optimal placement of ten piezoelectric sensor/actuator pairs mounted on cantilever plate is presented in (Hale and Daraji 2012).

In this paper, an observability-oriented approach is addressed. The presented method is based on developing a state model of a flexible structure including sensor locations. In this work, the placement of three accelerometers is optimized for a fully-clamped isotropic plate. First six eigenmodes are considered. Such assumptions make the analysis sufficiently general to consider both control complexity and application related aspects. The model is validated experimentally. Memetic algorithms (MA) are proposed to be applied to find optimal locations for sensors. MA algorithms, similar to evolutionary algorithms, are well adapted to searching for the global optimal solution for a complex problem such as the locations of sensors. MA algorithms are, however, characterized by improved local search procedures, and can lead to a faster convergence and a statistically better solution.

* Institute of Automatic Control, Silesian University of Technology, Akademicka 16, Gliwice, Poland, \{Stanislaw.Wrona, Marek.Pawelczyk\}@polsl.pl 


\section{PLATE MODELING}

In this Section, theoretical modeling of vibration of a thin plate with sensors bonded to its surface is presented. A state model is obtained using the Rayleigh-Ritz assumed mode shape method. Fundamental issues of this theory are recalled below to set a reference for further reading.

The governing equation for the dynamics of a Kirchhoff-Love plate in rectangular Cartesian coordinates is (Rao 2007):

$$
D\left(\frac{\partial^{4} w}{\partial x^{4}}+2 \frac{\partial^{4} w}{\partial x^{2} \partial y^{2}}+\frac{\partial^{4} w}{\partial y^{4}}\right)+m_{s} \frac{\partial^{2} w}{\partial t^{2}}=f
$$

where: $D=\frac{E h^{3}}{12\left(1-v^{2}\right)}$.

In (1) $w$ is the plate transverse displacement; $f$ is the total force acting on the plate; $\mathrm{D}$ is the flexural rigidity; $m_{s}$ is the mass per unit area of the plate surface. In (2) $E$ is the Young's modulus; $v$ is the Poisson's ratio; and $h$ is the plate thickness.

Considering only the transverse motion and neglecting the mass of sensors, the kinetic energy, $T$, and strain energy, $U$, of the plate can be written as:

$$
\begin{aligned}
& T=\frac{1}{2} \iint_{S} m_{s}\left(\frac{\partial w}{\partial t}\right)^{2} d x d y \\
& U=\frac{D}{2} \iint_{S}\left\{\left(\frac{\partial^{2} w}{\partial x^{2}}\right)^{2}+\left(\frac{\partial^{2} w}{\partial y^{2}}\right)^{2}+2 v \frac{\partial^{2} w}{\partial x^{2}} \frac{\partial^{2} w}{\partial y^{2}}\right. \\
& \left.\quad+2(1-v)\left(\frac{\partial^{2} w}{\partial x \partial y}\right)^{2}\right\} d x d y
\end{aligned}
$$

where $S$ is the surface of the plate.

In order to find a solution to the equation of plate motion (1) with given boundary conditions, the Rayleigh-Ritz method is employed (Leissa 1969). It is an approximate method based on the assumption that the solution can be expressed as a Ritz series, i.e.:

$$
w(x, y, t)=\sum_{i=1}^{M} \eta_{i}(x, y) q_{i}(t)
$$

where $q_{i}$ is the generalized displacement and $\eta_{i}$ is the $i$-th Ritz function. The Ritz functions need to satisfy the geometric boundary condition, so they are adopted as a product of eigenfunctions of a one-dimensional bar associated with $x$ and $y$ direction.

Kinetic and potential energies can be expressed with the use of the Ritz series, by substituting (5) into (3) and (4):

$$
\begin{aligned}
& T=\frac{1}{2} \sum_{i=1}^{M} \sum_{j=1}^{M}\left(\iint_{S} m_{s} \eta_{i} \eta_{j} d x d y \mid \dot{q}_{i} \dot{q}_{j},\right. \\
& U=\frac{D}{2} \sum_{i=1}^{M} \sum_{j=1}^{M}\left\{\int \int _ { S } \left[\frac{\partial^{2} \eta_{i}}{\partial x^{2}} \frac{\partial^{2} \eta_{j}}{\partial x^{2}}+\frac{\partial^{2} \eta_{i}}{\partial y^{2}} \frac{\partial^{2} \eta_{j}}{\partial y^{2}}+\ldots\right.\right. \\
& \left.\left.\ldots+2 v \frac{\partial^{2} \eta_{i}}{\partial x^{2}} \frac{\partial^{2} \eta_{j}}{\partial y^{2}}+2(1-v)+\frac{\partial^{2} \eta_{i}}{\partial x \partial y} \frac{\partial^{2} \eta_{j}}{\partial x \partial y}\right] d x d y\right\} \dot{q}_{i} \dot{q}_{j} .
\end{aligned}
$$

The kinetic and potential energies can also be expressed by means of generalized displacement vector $\mathbf{q}$, mass matrix $\mathbf{M}$, and stiffness matrix $\mathbf{K}$ :

$$
\begin{aligned}
& T=\frac{1}{2} \dot{\mathbf{q}}^{T} \mathbf{M} \dot{\mathbf{q}}, \\
& U=\frac{1}{2} \mathbf{q}^{T} \mathbf{K q} .
\end{aligned}
$$

Then, mass and stiffness matrices, $\mathbf{M}$ and $\mathbf{K}$, depend on the Ritz functions, and their components can be calculated as:

$$
\begin{aligned}
M_{i j} & =\iint_{S} m_{s} \eta_{i} \eta_{j} d x d y, \\
K_{i j} & =D \iint_{S}\left[\frac{\partial^{2} \eta_{i}}{\partial x^{2}} \frac{\partial^{2} \eta_{j}}{\partial x^{2}}+\frac{\partial^{2} \eta_{i}}{\partial y^{2}} \frac{\partial^{2} \eta_{j}}{\partial y^{2}}+2 v \frac{\partial^{2} \eta_{i}}{\partial x^{2}} \frac{\partial^{2} \eta_{j}}{\partial y^{2}}+\ldots\right. \\
& \left.\ldots+2(1-v) \frac{\partial^{2} \eta_{i}}{\partial x \partial y} \frac{\partial^{2} \eta_{j}}{\partial x \partial y}\right] d x d y .
\end{aligned}
$$

This leads to the equation of a vibrating structure:

$$
\mathbf{M} \ddot{\mathbf{q}}+\mathbf{K q}=\mathbf{Q}
$$

where $\mathbf{Q}$ is the vector of generalized forces. The harmonic solution to (12) yields the eigenvector matrix $\boldsymbol{\Phi}$ and eigenfrequencies $\omega_{i}$. Then, by replacing $\mathbf{q}$ by $\boldsymbol{\Phi v}$ (where $\mathbf{v}$ denotes a modal displacement vector), and multiplying (12) on the left by $\boldsymbol{\Phi}^{T}$, it gives:

$$
\ddot{\mathbf{v}}+\operatorname{diag}\left(\omega_{i}^{2}\right) \mathbf{v}=\boldsymbol{\Phi}^{T} \mathbf{Q}
$$

This equation can be written in a usual state-space form, using the state vector $\psi$ truncated at $N$ modes as (in the case considered in this paper, $N=6$ ):

$$
\begin{aligned}
& \boldsymbol{\psi}=\left[\dot{v}_{1}, \omega_{1} v_{1}, \dot{v}_{2}, \omega_{2} v_{2}, \ldots, \dot{v}_{N}, \omega_{N} v_{N}\right]^{T}, \\
& \frac{\partial}{\partial t} \boldsymbol{\psi}=\mathbf{A} \boldsymbol{\psi}+\mathbf{B u}, \\
& \mathbf{y}=\mathbf{C} \boldsymbol{\psi},
\end{aligned}
$$

with $2 N \times 2 N$ matrix $\mathbf{A}=\operatorname{diag}\left(\mathbf{A}_{i}\right)$, where:

$$
\mathbf{A}_{i}=\left[\begin{array}{cc}
-2 \xi_{i} \omega_{i} & -\omega_{i} \\
\omega_{i} & 0
\end{array}\right]
$$

The modal damping ratio, $\xi_{i}$, is determined experimentally by the use of impulsive excitation method. Matrix $\mathbf{C}$ is obtained by replacing $w$ by $\boldsymbol{\eta}^{T} \boldsymbol{\Phi v}$. In case of using accelerometers as sensors, the output is obtained by:

$$
\frac{\partial^{2} w}{\partial t^{2}}=\frac{\partial^{2}}{\partial t^{2}}\left(\boldsymbol{\eta}^{T} \boldsymbol{\Phi} \mathbf{v}\right)=\boldsymbol{\eta}^{T} \boldsymbol{\Phi} \ddot{\mathbf{v}}
$$

so the $i$-th component of a row of matrix $\mathbf{C}, \mathbf{c}=\left[\mathbf{c}_{l}, \mathbf{c}_{2}, \ldots, \mathbf{c}_{N}\right]$, can be expressed as:

$$
\mathbf{c}_{i}=\left.\boldsymbol{\eta}^{T} \boldsymbol{\varphi}_{i}\left[-2 \xi_{i} \omega_{i}-\omega_{i}\right]\right|_{x=x_{s}, y=y_{s}}
$$

where $\boldsymbol{\varphi}_{i}$ is the $i$-th column of $\boldsymbol{\Phi} ; x_{s}$ and $y_{s}$ are coordinates of the sensor centre. $\mathbf{C}$ contains as many rows as the number of sensors. 


\section{OPTIMIZATION CRITERION FOR SENSOR LOCATIONS}

The chosen objective function to be maximized expresses output energy received by the sensors, when the system starts in initial state $\psi_{0}$ and is not controlled (Fairman 1998):

$$
\left.E=\int_{0}^{\infty} \mathbf{y}^{T}(t) \mathbf{y}(t) d t=\boldsymbol{\psi}_{0}^{T} \int_{0}^{\infty} e^{\mathbf{A}^{T} t} \mathbf{C}^{T} \mathbf{C} e^{\mathbf{A}^{T} t} d t\right) \boldsymbol{\psi}_{0}=\boldsymbol{\psi}_{0}^{T} \mathbf{W}_{o} \boldsymbol{\psi}_{0},
$$

where $\mathbf{W}_{o}$ is the observability gramian matrix of dimension $2 N \times 2 N$. To maximize output energy with respect to the sensor locations, a measure of the gramian matrix should be maximized.

The observability gramian $\mathbf{W}_{o}$ can be calculated by solving the Lyapunov equation:

$$
\mathbf{A}^{T} \mathbf{W}_{o}+\mathbf{W}_{o} \mathbf{A}+\mathbf{C}^{T} \mathbf{C}=0 .
$$

If the $i$-th eigenvalue of $\mathbf{W}_{o}$, corresponding to the $i$-th eigenmode is small, the eigenmode is not observable well. To ensure the observability of $N$ first eigenmodes, the following criterion can be thus maximized:

$$
J=\min _{i=1, \ldots, 2 N} \lambda_{i}
$$

where $\lambda_{i}$ is the $i$-th eigenvalue of the observability gramian. Such a criterion concerns maximization of observability of the least observable eigenmode. It is dependent on matrix A (17), which is related to the structure itself, and matrix $\mathbf{C}$ (19), which is in turn related to the number, locations and type of sensors. As the number of sensors and considered eigenmodes increases, search space size expands and becomes more complex. Hence, memetic algorithms are proposed for solving the optimization problem.

\section{APPLICATION FOR A FULLY-CLAMPED PLATE}

The plate model developed in the previous Section has been validated experimentally for the case of a fully-clamped aluminum plate, of which the dimensions and characteristics are given in table 1. The described plate is used in following sections for the sensors placement optimization problem.

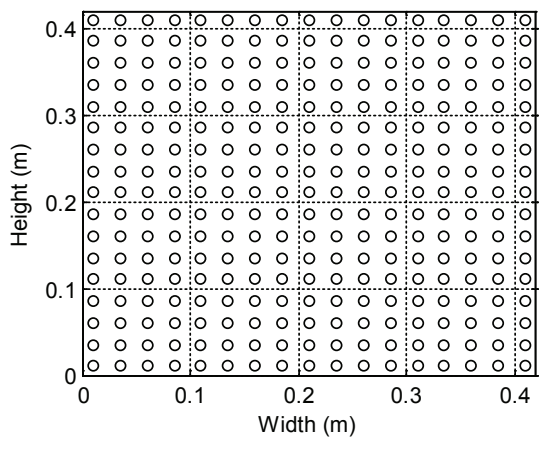

Fig. 1. Measurement points
The frequency responses of the plate due to acoustic excitation with a random signal were measured in 289 uniformly distributed points, depicted in figure 1, by the Polytec laser vibrometer PDV-100. This measurement was used to determine the eigenfrequencies of the plate, which are compared with the calculated values in table 2 .

Table 1

Mechanical and electrical characteristics

\begin{tabular}{|l|c|c|}
\hline Properties & Plate & PCB 356A17 \\
\hline Size, $\mathrm{mm}$ & $420 \times 420$ & $14 \times 14$ \\
\hline Thickness, $\mathrm{mm}$ & 1 & 20 \\
\hline Density, $\mathrm{kg} / \mathrm{m}^{3}$ & 2700 & - \\
\hline Mass, $\mathrm{kg}$ & 0.476 & 0.009 \\
\hline Young modulus, $\mathrm{GPa}$ & 70 & - \\
\hline Poisson's ratio & 0.35 & - \\
\hline Measurement range, $\mathrm{g} / \mathrm{pC}$ & - & \pm 10 \\
\hline Frequency range, $\mathrm{Hz}$ & - & 0.5 to 3000 \\
\hline
\end{tabular}

Table 2

Comparison of calculated and measured eigen frequencies

\begin{tabular}{|c|c|c|}
\hline Mode & Measurement, $\mathrm{Hz}$ & Rayleigh-Ritz method, $\mathrm{Hz}$ \\
\hline 1 & 50 & 51 \\
\hline 2 & 99 & 104 \\
\hline 3 & 104 & 104 \\
\hline 4 & 145 & 154 \\
\hline 5 & 179 & 186 \\
\hline 6 & 184 & 188 \\
\hline
\end{tabular}
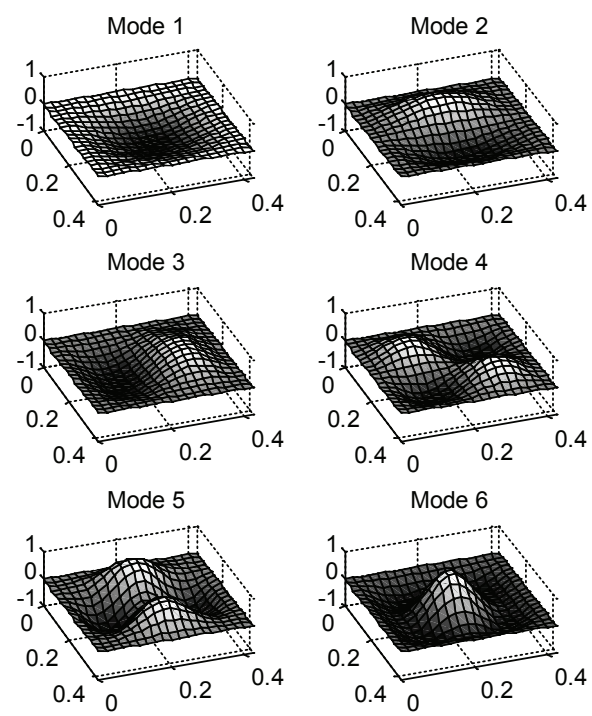

Fig. 2. First 6 eigenmodes shapes (size of the plate is in [m], and the $z$-axes depict normalized amplitudes) 
First six eigenmode shapes obtained by the Rayleigh-Ritz method, shown in figure 2, were consistent with the measured mode shapes. The frequencies of second and third eigenmodes that theoretically should be equal, in fact, differ slightly due to the brushing of the aluminum plate in one direction (it was observed that eigenmode, which has two half-waves in the direction perpendicular to the brushing has a lower frequency). Therefore, all considered eigenmodes should be distinguishable in the frequency domain. Frequency responses of the plate, averaged over the entire surface is presented in figure 3 (the numbers in parentheses depict the eigenfrequencies).

\section{COMPARISON OF GENETIC AND MEMETIC ALGORITHMS}

The considered optimization problem consists of determining the efficient locations of a fixed number of sensors. In this Section, specification of the used algorithms and a comparison of their performance is presented.
For both genetic (GA) and memetic (MA) algorithms, optimization variables are the sensors locations expressed in terms of spatial coordinates. The size of the population is kept the same for each iteration step. The best individuals are kept unchanged in the next generation (elitist selection). The termination criterion is satisfied if no improvement is found in the last $m$ iterations, or the maximum number of iterations is reached. For MA, the 'Hill climbing' technique is assumed as the individual learning strategy. Memetic algorithms are further described in (Wrona and Pawełczyk 2013).

Due to in-built local search procedures, MA involves more operations than GA in each generation. The extend of the additional computational load depends on chosen procedures and adopted parameters. For the study to be adequate, both algorithms should possess the same computational budget. Therefore, during the test, the population in GA consisted of 100 individuals, while the MA population had only 20 individuals. Such configuration resulted in a similar average computation time. The maximum number of generations was set to 30 .

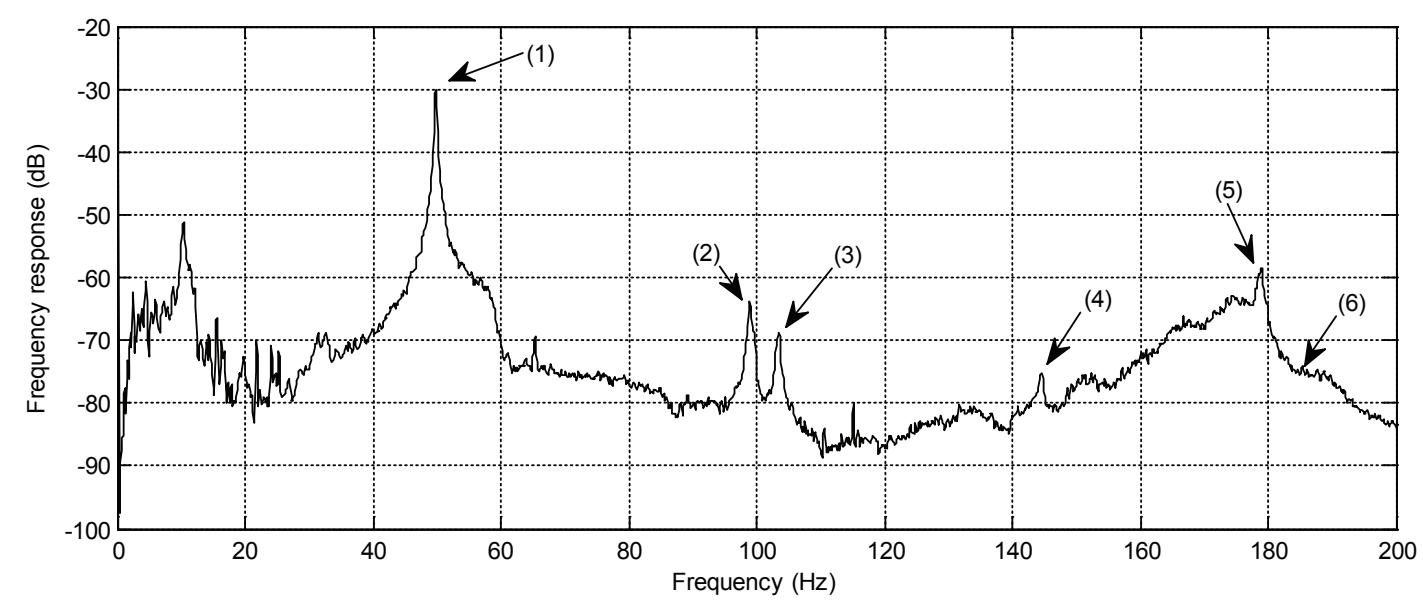

Fig. 3. Frequency response of the plate averaged over the entire surface

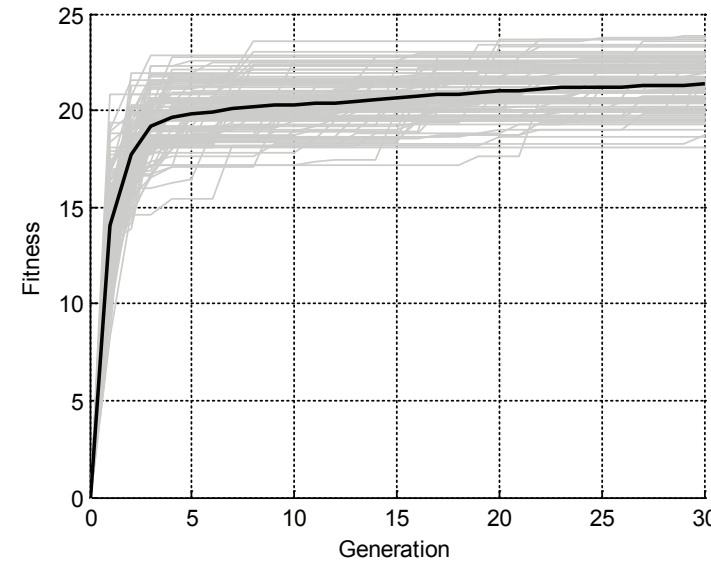

Fig. 4. Multiple runs of the genetic algorithm

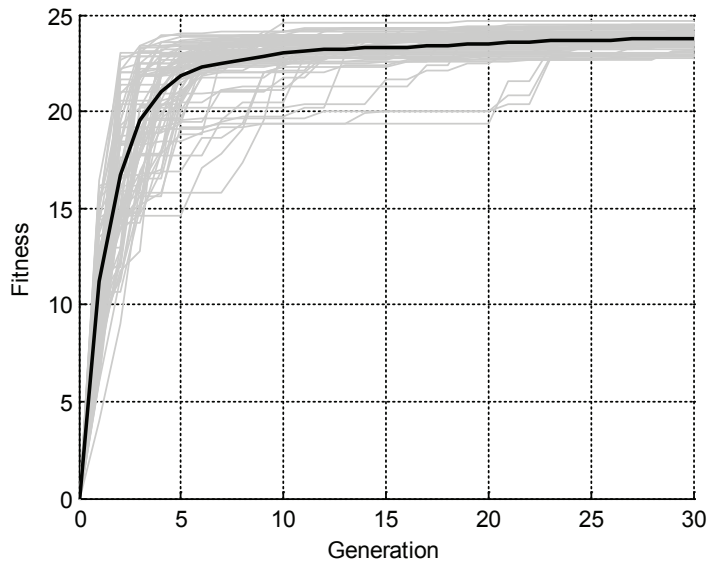

Fig. 5. Multiple runs of the memetic algorithm 
Both algorithms were started with a randomly generated initial population, which affects strongly the convergence rate. To obtain feasible statistical measures of their performance, each algorithm was run 100 times. Each particular run is presented in gray in figure 4 and 5, to highlight distribution of the possible results. The average result is shown as the bold black line. Algorithm parameters and results are summarized in table 3 .

The analysis shows that both algorithms are capable of reaching similar level of the fitness function and could be used successfully for solving the optimization problem. However, GA best solution is slightly worse than MA average solution, which demonstrates that MA provides noticeably better solutions. The consistency of the MA might also be considered as an advantage over the GA, because less runs would be necessary to ensure that the obtained solution is near the global optimum. This indicates a better computational efficiency in the final analysis. Additionally, if more complicated structures of multiple plates and with more sensors were considered, benefits of using the MA would be even more significant (Garg 2010).

Table 3

Comparison of characteristic values

\begin{tabular}{|l|c|c|}
\hline \multicolumn{1}{|c|}{ Properties } & $\begin{array}{c}\text { Genetic } \\
\text { algorithm }\end{array}$ & $\begin{array}{c}\text { Memetic } \\
\text { algorithm }\end{array}$ \\
\hline Runs & 100 & 100 \\
\hline Generations & 30 & 30 \\
\hline Population size & 100 & 20 \\
\hline Best final fitness & 23.80 & 24.70 \\
\hline Average final fitness & 21.37 & 23.82 \\
\hline Worst final fitness & 18.11 & 22.75 \\
\hline
\end{tabular}

\section{SENSOR PLACEMENT}

In this Section, application of the proposed method for optimal placement of three accelerometers is presented. The objective is to ensure the observability of first 6 eigenmodes, by maximizing the criterion (22). Details of the optimization algorithm are given in the previous Section. Characteristics of used sensors are given in table 1. Obtained eigenvalues of the observability gramian corresponding to the eigenmodes are presented in figure 6 . Sensors locations found are shown in figure 7.

Frequency responses of the plate due to acoustic excitation with a random signal, measured at obtained sensors locations, are presented in figures $8-10$. The numbers in parentheses depict theeigenfrequencies.

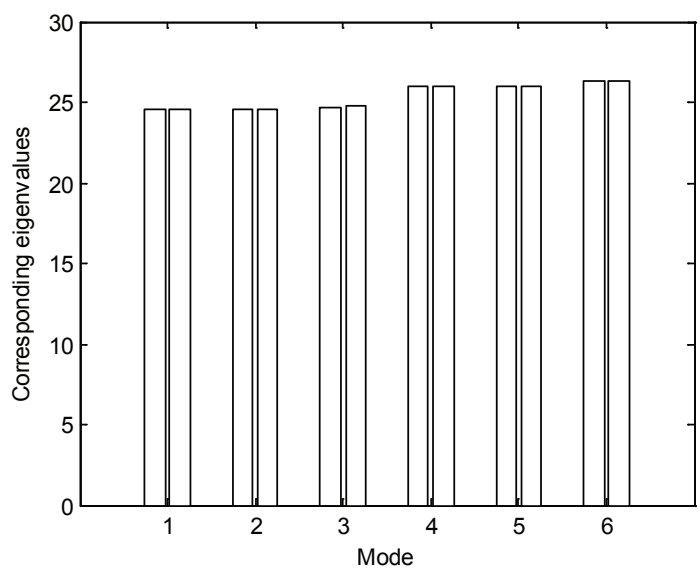

Fig. 6. Eigenvalues of the observability gramian matrix

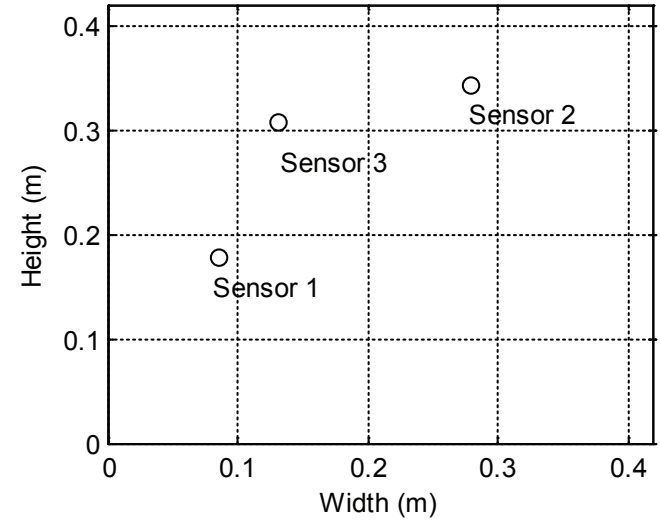

Fig. 7. Sensors locations

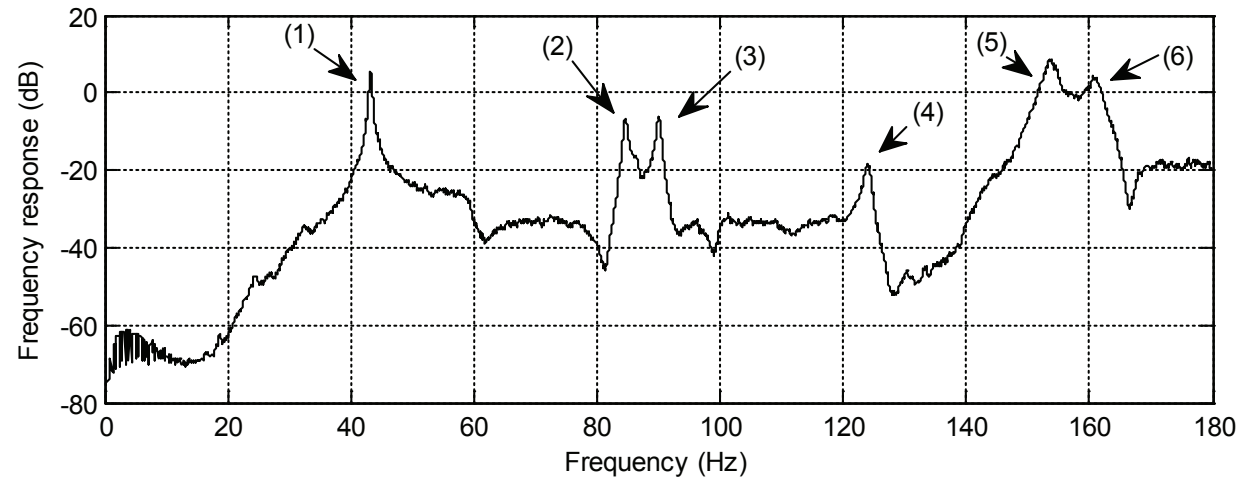

Fig. 8. Frequency response at the location of sensor 1 


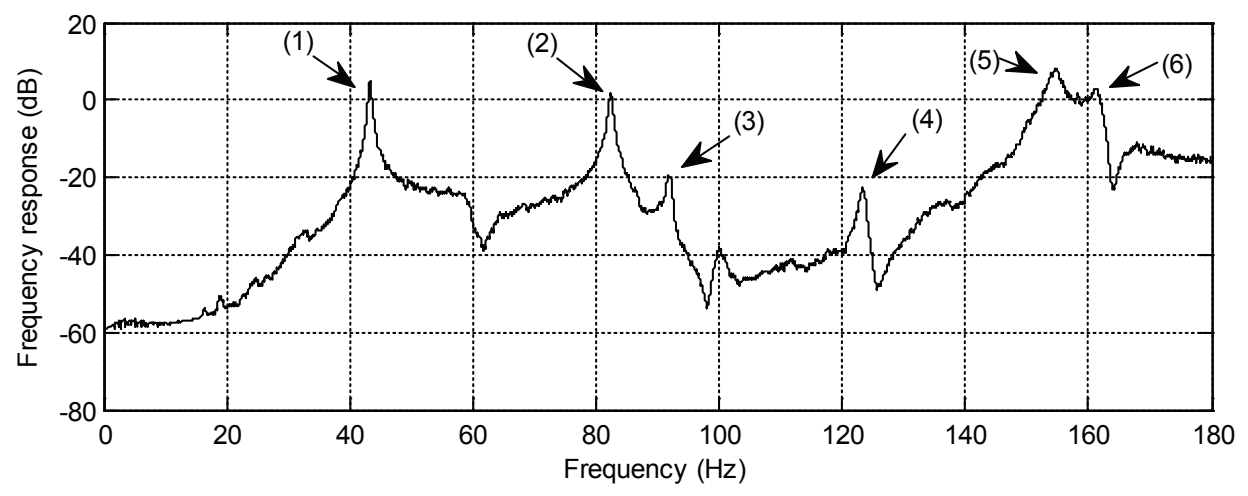

Fig. 9. Frequency response at the location of sensor 2

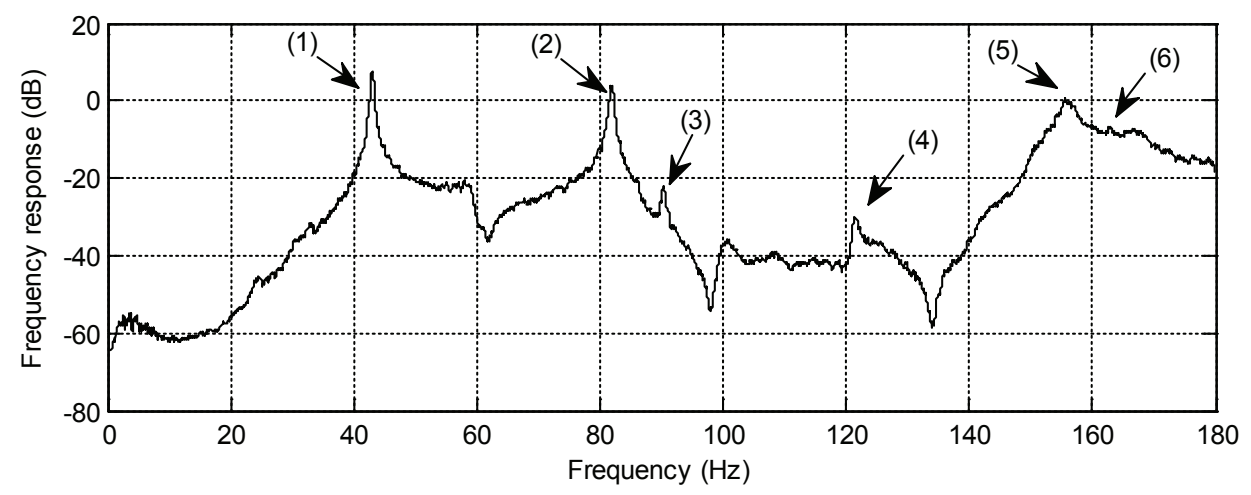

Fig. 10. Frequency response at the location of sensor 3

The observability of the given eigenmode is practically meaningful if the corresponding peak is distinguishable in the frequency response graph. As shown in figures 8-10, individual sensors complement each other. Every sensor clearly sees the first eigenmode. However, the third mode is well seen by sensor 1, while it is faint for sensor 2 and 3 . Hence, each desired eigenmode is observable with acceptable margin.

The results presented above have concerned a given number of sensors and frequency range. However, studies have also been performed for other numbers of sensors and frequency ranges. It follows from the analysis that increasing the frequency bandwidth, while maintaining a constant number of sensors, results in decreasing the level of observability. Thus, in practical applications, where limitations in the number of sensors are set, the frequency band, for which the algorithm is able to find efficient locations is also limited.

\section{CONCLUSION}

A theoretical model of a thin plate with sensors bonded to its surface has been derived in this paper. The Rayleigh-Ritz assumed mode shape method has been used. The model is applicable for different boundary conditions, depending on the chosen Ritz functions. A laser vibrometer has been employed to verify the suitability of the modeling in the case of a fully-clamped aluminum plate.
An observability-oriented objective function has been presented and used to optimize locations of three accelerometers. The first six eigenmodes of the plate have been considered. The purpose of the optimization criterion is to ensure each mode of the structure to be observable. Memetic algorithms have been proposed to find optimal locations. The analysis shows high computational efficiency and capability of finding statistically better solutions than genetic algorithm. Theoretical results have been confirmed by real-world experiments.

\section{Acknowledgments}

The research reported in this paper has been supported by the National Science Centre, decision no. DEC-2012/07/B/ ST7/01408.

The authors would also like to thank EC Test Systems, Krakow, Poland, for providing Polytec laser vibrometer PDV-100 to experimentally validate obtained results.

\section{References}

Fairman F.W. 1998, Linear Control Theory: The State Space Approach. Wiley, ISBN 0471974897, p. 94.

Garg P. 2010, A Comparison between Memetic algorithm and Genetic algorithm for the cryptanalysis of Simplified Data Encryption Standard algorithm. International J. of Network Security \& Its Applications, vol. 1, No. 1, pp. 34- 42 . 
Górski P., Kozupa M. 2012, Variable Sound Insulation Structure with MFC Elements. Archives of Acoustics, vol. 37, No. 1, pp. 115-120.

Hale J.M., Daraji A.H. 2012, Optimal placement of sensors and actuators for active vibration reduction of a flexible structure using a genetic algorithm based on modified $H_{\infty}$. J. of Phys.: Conference Series, vol. 382, No. 1, pp. 12036-12041.

Kozupa M., Wiciak J. 2010, Comparison of passive and active methods for sound radiation reduction from the clamped plate. Mechanics and Control, vol. 29, No. 3, pp. 128-131.

Kumar K.R., Narayanan S. 2007, The optimal location of piezoelectric actuators and sensors for vibration control of plates, Smart Materials and Structures, vol. 16, No. 6, pp. 2680-2691.

Leissa A.W. 1969, Vibration of plates. Washington DC, NASA, ISBN 1563962942 , p. 41.

Leleu S., Abou-Kandil H., Bonnassieux Y. 2001, Piezoelectric actuators and sensors location for active control of flexible structures. IEEE Transactions on Instrumentation and Measurement, vol. 50, No. 6, pp. 1577-1582.

Leniowska L. 2011, An Adaptive Vibration Control Procedure Based on Symbolic Solution of Diophantine Equatio. Archives of Acoustics, vol. 36, No. 4, pp. 901-912.
Liu W., Hou Z., Demetriou M.A. 2006, A computational scheme for the optimal sensor/actuator placement of flexible structures using spatial $\mathrm{H}_{2}$ measures. Mechanical systems and signal processing, vol. 20, No. 4, pp. 881-895

Mazur K., Pawełczyk M. 2011, Active noise-vibration control using the filtered-reference LMS algorithm with compensation of vibrating plate temperature variation. Archives of Acoustics, vol. 36, No. 1 , pp. 65-76.

Pawełczyk M. 2008, Active noise control-a review of control-related problems. Archives of Acoustics, vol. 33, No. 4, pp. 509-520.

Rao S. 2007, Vibration of continuous systems. Wiley, ISBN 0471771716 , p. 464

Szemela K., Rdzanek W.P., Rdzanek W.J. 2012, Acoustic Power Radiated by a System of Two Vibrating Circular Membranes Located at the Boundary of Three-Wall Corner Spatial Region. Archives of Acoustics, vol. 37, No. 4, pp. 463-473.

Wrona S., Pawełczyk M. 2013, Controllability-oriented placement of actuators for active noise-vibration control of rectangular plates using a memetic algorithm. Archives of Acoustics, vol. 38, No. 4, pp. 529-536. 